\title{
A Six-Armed Phenhomazine Ligand with a Potential "Turn-Off" Copper(II) Sensing Capability through Terbium(III) Luminescence Quenching
}

\author{
Leandro Trupp, ${ }^{[a, b, c, d, e]}$ Andrea C. Bruttomesso ${ }^{\dagger}{ }^{[c, d]}$ Svetlana V. Eliseeva, ${ }^{[e]}$ \\ Stéphane Petoud, ${ }^{[\mathrm{e}]}$ Javier A. Ramírez, ${ }^{*[\mathrm{c}, \mathrm{d}]}$ and Beatriz C. Barja ${ }^{*[a, b]}$
}

To An, in loving memory

Abstract: Herein, the design, synthesis, and characterization of a phenhomazine ligand are described. The ligand has six pendant acetate arms designed for the combined coordination of copper(II) and lanthanide(III) ions, with the perspective of developing a "turn-off" copper sensor. The key step for the ligand preparation was the one-step endomethylene bridge fission of a diamino Tröger's base with a concomitant alkylation. Fluorescence and absorption spectroscopies as well as nuclear magnetic resonance (NMR) experiments were performed to analyze and understand the coordination properties of the ligand. Transition metal coordination was driven by the synergistic effect of the free nitrogen atoms of the diazocinic core and the two central acetate arms attached to those nitrogen atoms, whereas lanthanide coordination is performed by the external acetate arms, presumably forming a self-assembled 2:2 metallosupramolecular structure. The terbium complex shows the typical green emission with narrow bands and long luminescence lifetimes. The luminescence quenching produced by the presence of copper(II) ions was analyzed. This work sets, therefore, a starting point for the development of a phenhomazine-based "turn-off" copper(II) sensor.

\section{Introduction}

Copper(II) plays a crucial role in biological and environmental processes, as it is highly toxic for microorganisms such as algae, fungi, and many bacteria, and essential for humans, ani-

[a] Dr. L. Trupp, Dr. B. C. Barja

Departamento de Química Inorgánica, Analítica y Química Física Facultad de Ciencias Exactas y Naturales, Universidad de

Buenos Aires, Int. Güiraldes 2160, Ciudad Universitaria Buenos Aires, 1428 (Argentina)

E-mail:barja@qi.fcen.uba.ar

[b] Dr. L. Trupp, Dr. B. C. Barja

Instituto de Química Física de los Materiales, Medio Ambiente y Energía (INQUIMAE), CONICET_Universidad de Buenos Aires Int. Güiraldes 2160, Ciudad Universitaria, Buenos Aires, 1428 (Argentina)

[c] Dr. L. Trupp, Dr. A. C. Bruttomesso, Dr. J. A. Ramírez Departamento de Química Orgánica, Facultad de Ciencias Exactas y Naturales, Universidad de Buenos Aires Int. Güiraldes 2160, Ciudad Universitaria, Buenos Aires, 1428 (Argentina) E-mail:jar@qo.fcen.uba.ar

[d] Dr. L. Trupp, Dr. A. C. Bruttomesso, Dr. J. A. Ramírez Unidad de Microanálisis y Métodos Físicos Aplicados a Química Orgánica (UMYMFOR), CONICET-Universidad de Buenos Aires, Int. Güiraldes 2160 Ciudad Universitaria, Buenos Aires, 1428 (Argentina)

[e] Dr. L. Trupp, Dr. S. V. Eliseeva, Dr. S. Petoud Centre de Biophysique Moléculaire, Centre National de la Recherche Scientifique (CNRS), UPR 4301, 45071 Orléans Cedex 2 (France)

[†] Deceased, 25th August 2018.

$\square$ Supporting information and the ORCID identification number(s) for the

iD author(s) of this article can be found under: https://doi.org/10.1002/chem.202002282. mals, and plants. ${ }^{[1,2]}$ In humans, deficiency of $\mathrm{Cu}^{\prime \prime}$ as well as its excess can induce numerous diseases, for example, these related to brain function such as Alzheimer's and Parkinson's diseases, or prion disorders and cancer progression. ${ }^{[3-5]}$ Thus, the detection and determination of copper(II) in complex samples is of paramount importance, but remains difficult by direct spectroscopic methods as it is silent for most of them.

A very promising method for copper(II) detection is centered on the use of lanthanide(III)-based luminescent sensors. The working principle of most of these sensors is based on the quenching of the lanthanide(III) luminescence by the presence

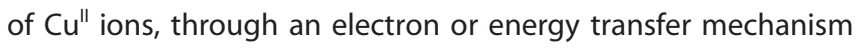
to/from the excited lumophore and through paramagnetic effects. ${ }^{[6-9]}$ These processes, when combined with the unique optical properties of lanthanide(III) ions, that is, sharp emission bands, large energy difference between absorption and emission bands, and long luminescence lifetimes, allow the design of "turn-off" sensors, in which the presence of copper(II) ions is detected through the diminution of the lanthanide(III) luminescence signal. ${ }^{[9-14]}$ Moreover, some of the lanthanide(III) ions, namely terbium(III) and europium(III), emit in the visible region of the electromagnetic spectrum, and can thus be easily recognized by the naked eye. ${ }^{[15-17]}$

Nevertheless, the extremely low light absorption of lanthanide(III) ions, attributable to the forbidden nature of most of $f-f$ transitions, makes it essential to create ligands that allow both complexation of $\mathrm{Ln}^{\mathrm{III}}$ ions and sensitization of their emission. ${ }^{[15-17]}$ In this regard, podands are a type of ligands of par- 
ticular relevance, as they are usually synthetically accessible and easy to derivatize for the introduction of the suitable functional groups for further applications. ${ }^{[17-19]}$ Moreover, the flexibility of many podands allows their optimal orientation around lanthanide(III) ions to protect them from the environment.

Inspired by Harmata's work, ${ }^{[20]}$ who synthesized a 5,6,11,12tetrahydrophenhomazine (THP) derived ligand with pendant arms for $\mathrm{Zn}$ " complexation (Figure 1), we envisioned the preparation of a THP with dual coordination potential, both for lanthanide(III) ions such as Tb"II or Eu"II and for Cu". THPs are flexible dibenzodiazocines structurally related to Tröger's bases (TBs), the loss of the endomethylene bridge of which results in the flexibilization of the mesocyclic scaffold and makes the nitrogen atoms available for metal complexation. ${ }^{[21-23]}$

In addition to copper coordination via the nitrogen atoms, we sought lanthanide complexation through the presence of acetate groups, given that lanthanide ions are hard Lewis acids and thus they favor coordination with anionic carboxylate

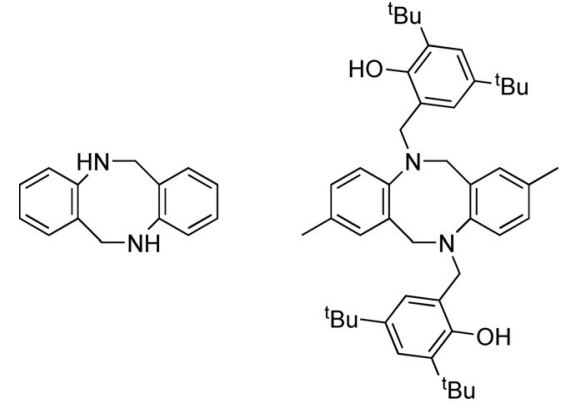

THP
Harmata's ligand

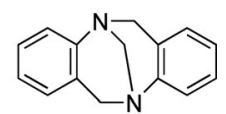

Figure 1. Structure of Harmata's ligand and parent general structures THP and TB. groups over nitrogen atoms. ${ }^{[18,24]}$ Thus, we designed the phenhomazine ligand 1 (Scheme 1) with six pendant acetate arms, the four external ones aiming at the coordination with lanthanide ions and two central arms that should favor the transition metal coordination by formation of five-membered rings, as was demonstrated for a DACO (1,5-diazacyclooctane) derivative. ${ }^{[25]}$ In addition, the $p$-phenylenediamine moieties could act efficiently as antennas for lanthanide luminescence sensitization. ${ }^{[26]}$

A simple way of accessing $\mathrm{N}$-substituted THPs is via the fission of the endomethylene bridge of a TB. This can be performed in a sequential fashion as done in Harmata's work, with the removal of the methylene bridge followed by the alkylation of the resulting secondary amines. ${ }^{[20]}$ Alternatively, both reactions could occur concomitantly in only one step when Tröger's bases are treated with alkylating agents, as several reports show. ${ }^{[27-29]}$

In this work, we propose the synthesis of the compound 1 by a strategy that, starting from the diamino-TB 2, allows the incorporation of the acetate pendant arms on both central nitrogens as well as on the exocyclic nitrogens in one step. We also present the studies regarding the complexation properties of 1 , along with a preliminary exploration of its potential use as a copper "turn-off" sensor.

\section{Results and Discussion}

\section{Compound synthesis}

As stated above, the synthetic route proposed for the synthesis of ligand 1 was designed having in mind the simultaneous fission of the endomethylene bridge of the diamino-TB 2 and the alkylation of the four nitrogen atoms. Compound $\mathbf{2}$ was prepared according to the procedure described by Kiehne
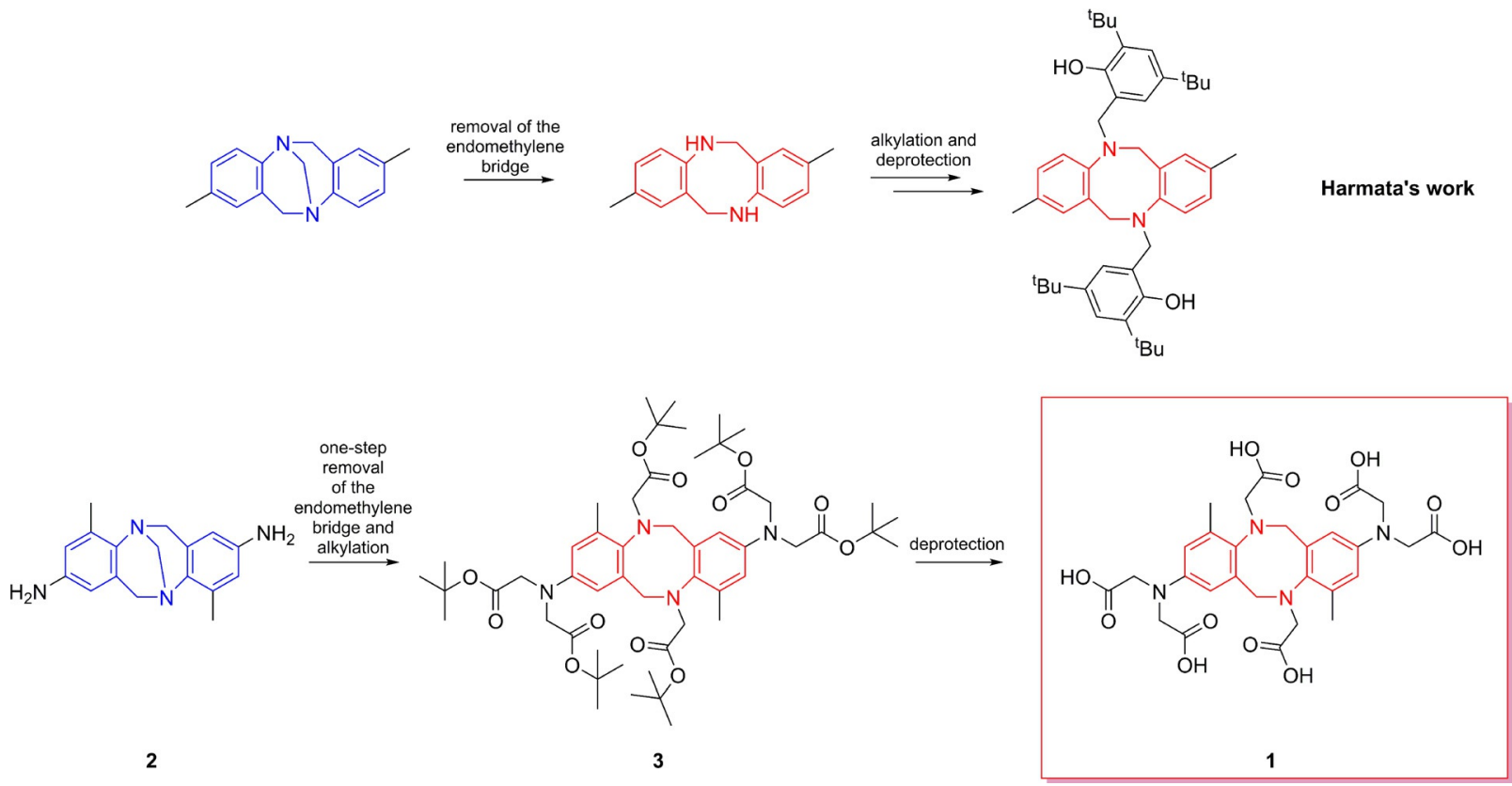

This work

Scheme 1. Key steps for phenhomazine syntheses in Harmata's work (top) and in this work (bottom). 
<smiles>Cc1cc([N+](=O)[O-])ccc1N</smiles>

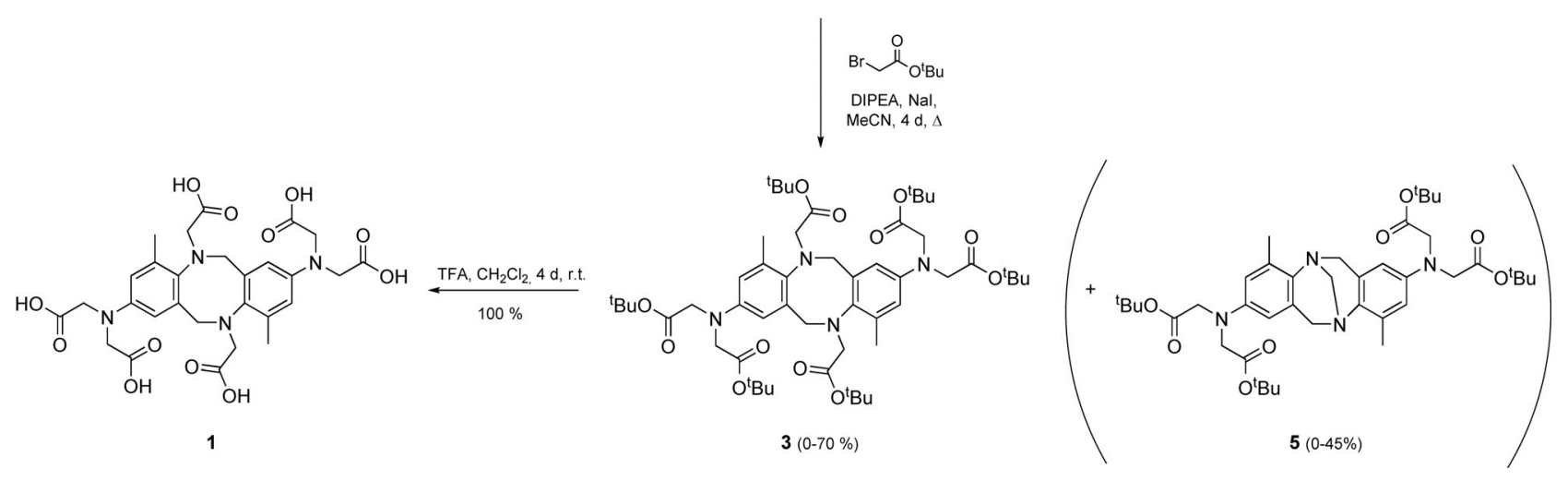

Scheme 2. Synthetic route employed for the synthesis of ligand 1.

et al., ${ }^{[30]}$ starting from 2-methyl-4-nitroaniline via an acid-catalyzed condensation step with paraformaldehyde and the subsequent reduction of the resulting dinitro-TB 4, as shown in Scheme 2.

We selected tert-butyl bromoacetate as the alkylating agent owing to the ease of removal of the tert-butyl group and used the experimental conditions proposed by Liu et al..$^{[31]}$ The reaction was performed in acetonitrile heated at reflux as the solvent, adding diisopropylethylamine as a base for neutralizing the generated acidic media, along with the incorporation of sodium iodide as an additive to favor the electrophilicity of the alkylating agent. Different amounts of the alkylating agent, sodium iodide, and reaction times were explored to identify the most suitable conditions for obtaining the desired product. The results are summarized in Table 1.

\begin{tabular}{|llllll|}
\hline \multicolumn{3}{|l|}{ Table 1. Experimental conditions assessed for the preparation of 3.} \\
Condition & $\begin{array}{l}\text { tert-Butyl bromoacetate } \\
\text { [equiv] }\end{array}$ & $\begin{array}{l}\text { Nal } \\
\text { [equiv] }\end{array}$ & $\begin{array}{l}t \\
\text { [days] }\end{array}$ & $\begin{array}{l}\mathbf{3} \\
{[\%]}\end{array}$ & $\begin{array}{l}\mathbf{5} \\
{[\%]}\end{array}$ \\
\hline a & 9.6 & 1.25 & 4 & 70 & - \\
b & 6.0 & 1.25 & 4 & 46 & 22 \\
c & 6.0 & - & 4 & 26 & 45 \\
d & 4.2 & - & 2 & - & 34 \\
\hline
\end{tabular}

First, we found that in some conditions compound $\mathbf{3}$ was obtained with significant amounts of the tetraalkylated TB 5, the formation of which could be avoided when longer reaction times and excess of alkylating agent were used. The presence of sodium iodide also favored the formation of 3, possibly by increasing the electrophilicity of the alkylating agent and by stabilizing ionic intermediate species. ${ }^{[32-35]}$ Interestingly, a hypothetical compound only alkylated at the central nitrogen atoms but not at the exocyclic arylamines was never detected, confirming that alkylation of the anilines is favored over the breakdown of the endomethylene bridge.
The formation of the hexaester $\mathbf{3}$ was confirmed through mass spectrometry and NMR spectroscopy (Figures S1-S6, Supporting Information). ${ }^{1} \mathrm{H}$ and ${ }^{13} \mathrm{C}$ NMR spectra of $\mathbf{3}$ showed a complex array of signals, which is consistent with the presence of two conformers in equilibrium. This assumption was confirmed by EXSY bidimensional NMR (Figure S6, Supporting Information), which shows the cross-peaks associated with a magnetization transfer between two sites that undergo chemical exchange, indicating that the conversion between the conformers is in a fast exchange regime on the relaxation timescale, even when it is in the slow exchange limit on the NMR chemical shift timescale. ${ }^{[36]}$

In a further step, the tert-butyl esters of phenhomazine $\mathbf{3}$ were readily hydrolyzed with trifluoroacetic acid (TFA) to obtain the desired ligand 1, the structure of which was also confirmed by mass spectrometry (HR-ESI) and 1D and 2D NMR spectroscopy (Figures S7-S11 and S21, Supporting Information), and whose photophysical properties were studied (Figure S22 and Table S1, Supporting Information).

\section{Copper(II) coordination}

A spectrophotometric titration of the solution containing compound 1 with copper(II) chloride was performed (Figure 2). Methanol was chosen as the solvent because both the organic and the ionic compounds exhibit sufficient solubility. An analysis of the ultraviolet region of the spectra revealed that an addition of up to one equivalent of $\mathrm{Cu}^{\prime \prime}$ induces a significant decrease of the absorbance of the main band, centered at approximately $250 \mathrm{~nm}$. The presence of three isosbestic points (at $244 \mathrm{~nm}, 275 \mathrm{~nm}$, and $304 \mathrm{~nm}$ ) suggests the existence of at least two species in equilibrium, the free phenhomazine and a 1:1 Cu" complex.

An increase of the concentration of $\mathrm{Cu}^{\text {Il }}$ above one equivalent resulted in a rise in the absorption of the whole spectrum with disappearance of the isosbestic points. We suggest that such behavior is not associated with a change in the metal co- 


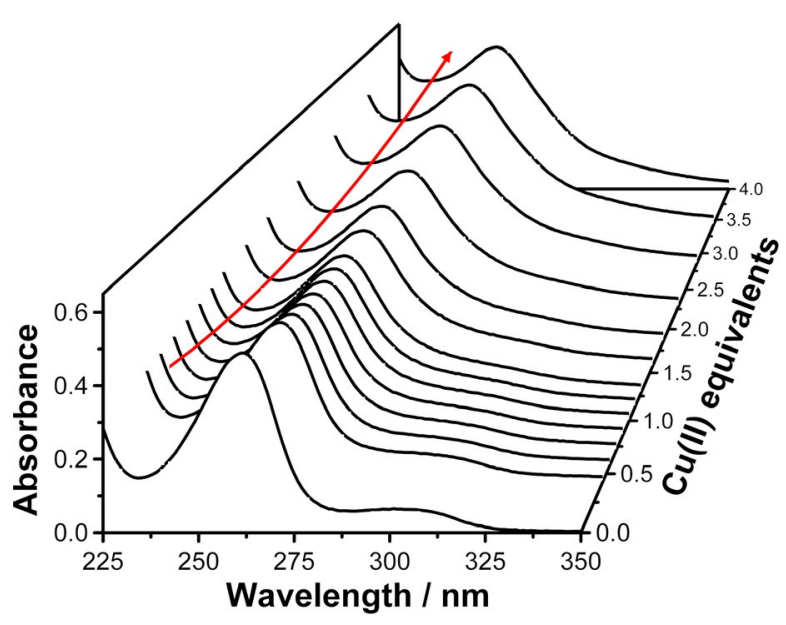

Figure 2. Spectrophotometric titration of $1\left(2.7 \times 10^{-5} \mathrm{M}\right)$ with $\mathrm{CuCl}_{2}$ in methanol.

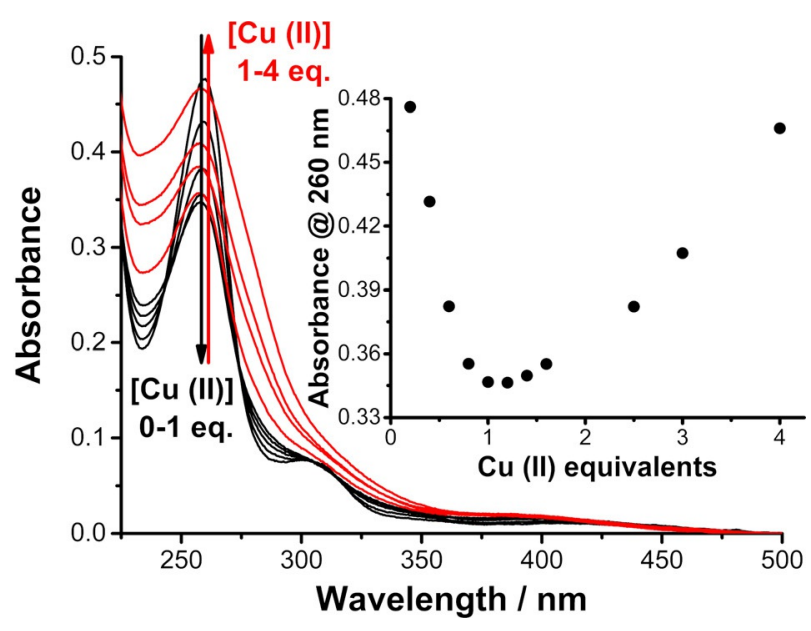

ordination but is directly related to the excess of $\mathrm{Cu}^{\text {II }}$ in solution and the formation of copper-solvent complexes [Cu$\left.(\mathrm{MeOH})_{6-n} \mathrm{Cl}_{n}\right]^{2-n}$. It was described that such complexes exhibit large molar absorptivities with values of up to $5 \times 10^{3} \mathrm{M}^{-1} \mathrm{~cm}^{-1}$ in the $200-300 \mathrm{~nm}$ spectral region. ${ }^{[37]}$

Having confirmed the coordination of $\mathrm{Cu}^{\prime \prime}$, we set out to investigate whether the driving force of this phenomenon was caused by the presence of the nitrogen atoms of the diazocinic core, the acetate arms or the synergistic effect of the both of them. To that end, we hydrolyzed the byproduct 5, which originates a Tröger's base 6 with four acetate pendant arms (Scheme 3). NMR spectra of compounds 5 and $\mathbf{6}$ are presented in Figures S12-S15 and S16-S21 (Supporting Information), respectively.

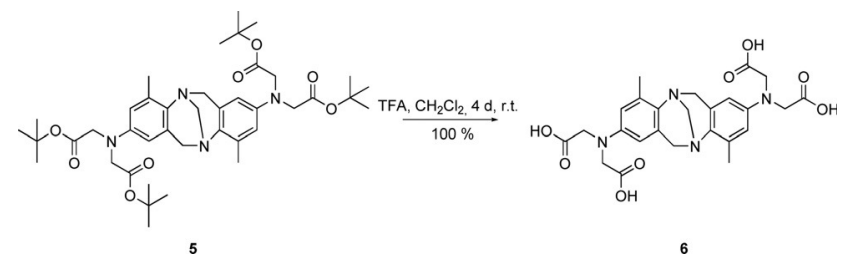

Scheme 3. Preparation of 6 from byproduct 5 .

The TB 6 and the tert-butyl ester $\mathbf{3}$ were subjected to spectrophotometric titrations with $\mathrm{Cu}^{\prime \prime}$ in the same way as performed for 1 . In both cases, a rise in the absorbance was observed at every wavelength upon the addition of $\mathrm{Cu}^{\prime \prime}$, without the presence of isosbestic points and with no significant change of the trend after addition of one equivalent of $\mathrm{Cu}^{\prime \prime}$ (Figure S23, Supporting Information). These results suggest that neither $\mathbf{3}$ nor 6 have the ability to coordinate $\mathrm{Cu}^{\prime \prime}$, which in turn demonstrates that both the central nitrogen atoms of the phenhomazine and the unprotected central acetate arms are necessary for proper coordination of Cull by 1 .

To get a deeper insight concerning the coordination mode of $\mathrm{Cu}^{\prime \prime}$ with 1, a new titration was performed by using ${ }^{1} \mathrm{H}$ NMR spectroscopy. Owing to the paramagnetic nature of $\mathrm{Cu}^{\prime \prime}$, the diamagnetic ion $\mathrm{Zn}^{\text {" }}$ was used as a model, as several reports show that the coordination mode and stoichiometry should not vary substantially between these two ions. ${ }^{[21,22,38,39]}$

Figure 3 shows the regions of the ${ }^{1} \mathrm{H}$ NMR spectrum that are more strongly affected by $\mathrm{Zn} \|$ addition and correspond to the signals of the diazocinic core. In particular, the signals with a larger chemical shift variation are those belonging to the methylenes of the central acetate arms and to the high-field hydrogen of the diazocinic core methylenes $\left(\mathrm{H}-6 / 12_{\mathrm{B}}\right)$.

These experimental results indicate that the ligand coordinates the $Z n^{\|}$ion through the central nitrogen atoms and not through the external acetate arms. Variation of chemical shifts of the aforementioned signals was significant up to the addition of one equivalent of metal, reaching nearly constant values afterwards. This fact corroborates the presence of a 1:1 complex.

The structure proposed for the 1:1 $\mathrm{Cu}^{2+}-1$ complex is shown in Figure 4, and involves the adoption of a boat-like

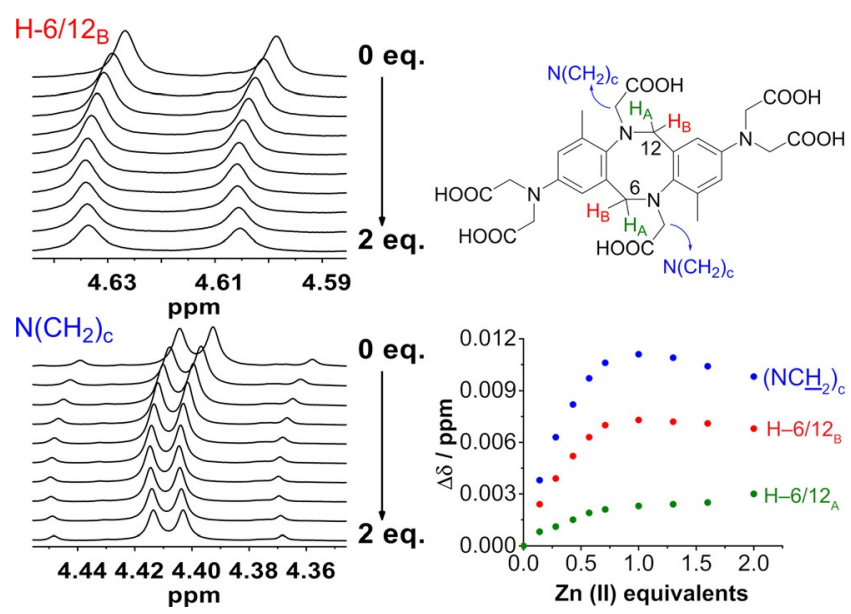

Figure 3. NMR titration of 1 with $\mathrm{Zn}\left(\mathrm{NO}_{3}\right)_{2}$ in $\mathrm{CD}_{3} \mathrm{OD}$. Regions of the ${ }^{1} \mathrm{H}$ NMR $(500 \mathrm{MHz})$ spectra for the signals $\mathrm{H}-6 / 12_{\mathrm{B}}$ (left, top) and $\left(\mathrm{NCH}_{2}\right)_{\mathrm{C}}$ (left, bottom) and chemical shift variation $\Delta \delta$ for the most sensitive signals as a function of the $\mathrm{Zn}^{\text {"l }}$ equivalents added, with respect to the pure ligand (right). 


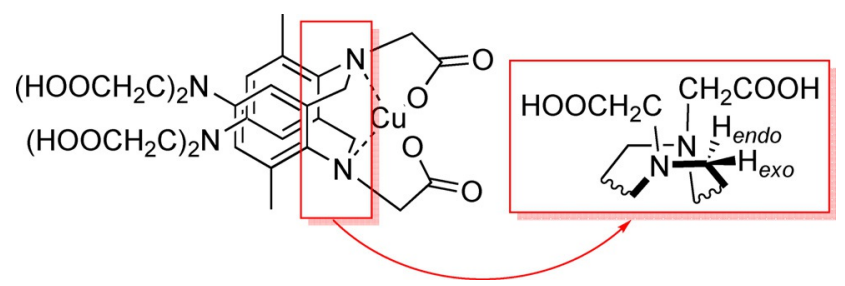

Figure 4. Possible structure of the 1:1 $\mathrm{Cu}^{2+}-1$ complex with ligand in a boat-like conformation.

conformation, which has already been identified or suggested for similar complexes. ${ }^{[20,22,25,40]}$ This conformation would present one of the $6 / 12$ hydrogens toward the interior of the diazocine core (endo) and one toward the exterior (exo), which is consistent with the NMR titrations presented above. In addition, the endo hydrogen would be significantly more affected by the coordination than the exo, and by analogy with TBs, it is reasonable to assume that the high-field signal $H-6 / 12_{B}$ is the endo proton.

\section{Lanthanide(III) coordination}

Sensitization of lanthanide(III) luminescence through ligand irradiation was monitored by spectrofluorimetric titrations of 1 with europium(III) or terbium(III) triflates in methanol. In solutions containing $\mathrm{Eu}(\mathrm{OTf})_{3}$ and 1, europium emission was found to be negligible, reflecting an inefficient sensitization or the presence of strong quenching processes through ligand-tometal charge transfer (LMCT) states. ${ }^{[18,26,41,42]}$ On the other hand, in solutions containing $\mathrm{Tb}(\mathrm{OTf})_{3}$ and 1 , the excitation into the ligand-centered bands at $320 \mathrm{~nm}$ generates a green luminescence with narrow emission bands centered at 488, 545,585 , and $620 \mathrm{~nm}$ that can be assigned to the ${ }^{5} \mathrm{D}_{4} \rightarrow{ }^{7} \mathrm{~F}_{J} \mathrm{~Tb}^{111}$ transitions $(J=6-3)$. Therefore, the ligand 1 can act as an efficient sensitizer of Tb" luminescence.

Analysis of spectrofluorimetric titrations of 1 with $\mathrm{Tb}(\mathrm{OTf})_{3}$ indicates the formation of a 1:1 complex as the most emissive species (Figure 5). An excess of $\mathrm{Tb}(\mathrm{OTf})_{3}$ results in a decrease of the luminescence intensity up to the addition of two equivalents of $\mathrm{Tb}^{\mathrm{III}}$, when a change of the slope occurs. This $2: 1 \mathrm{~Tb}^{\mathrm{III} /}$ ligand ratio complex exhibits much weaker luminescence than that of the 1:1 complex. Excitation and emission spectra of the
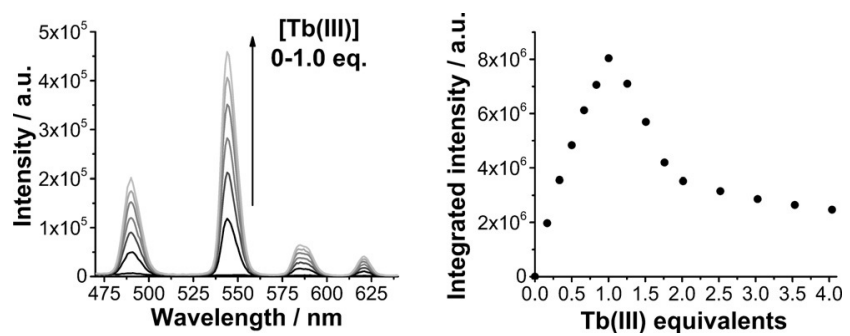

Figure 5. Spectrofluorimetric titration of $1\left(7.6 \times 10^{-6} \mathrm{M}\right)$ with $\mathrm{Tb}(\mathrm{OTf})_{3}$ in methanol. Left: $\mathrm{Tb}^{\mathrm{III}}$ emission spectra for $0-1.0$ equivalents of $\mathrm{Tb}(\mathrm{OTf})_{3}$ added; right: integrated emission intensity of the four ${ }^{5} D_{4} \rightarrow{ }^{7} F_{J}(J=6-3)$ bands $\left(\lambda_{\text {exc }}=320 \mathrm{~nm}\right)$.
1:1 $\mathrm{Tb}^{\mathrm{III}}-\mathbf{1}$ complex are presented in Figure S24 (Supporting Information).

The 1:1 complex exhibits a $1.9 \%$ luminescence quantum yield, with an observed emission lifetime in methanol of $1.2 \mathrm{~ms}$ (Figure S25, Supporting Information). The same lifetime was measured in monodeuterated methanol $\left(\mathrm{CH}_{3} \mathrm{OD}\right)$, indicating that all coordination positions of the lanthanide are occupied by the ligand and no solvent molecules are directly coordinated to the Tb"II ion (Figure S26, Supporting Information). ${ }^{[43]}$ This fact is consistent with a boat-like conformation where the four external acetate arms could coordinate the terbium(III) ion, as they point in the same direction.

Nevertheless, a 2:2 Tb" ${ }^{\text {III }}-1$ complex is also feasible, with each $\mathrm{Tb}^{\mathrm{III}}$ ion coordinated by two acetate arms from each ligand 1 (Figure 6). For example, 2:2 metallosupramolecular self-assembled structures have been ubiquitously found by Lützen's group for complexes formed by TBs and transition metal ions, in which the V-shaped structure of the TB scaffold favors a rhombic system with two ligands and two ions at the respective vertices. ${ }^{[30,44-47]}$ In the case of lanthanide(III) ions, 2:2 metallosupramolecular entities are known and in some cases were also found as key stable intermediates in the formation of more complex structures. ${ }^{[48-51]}$

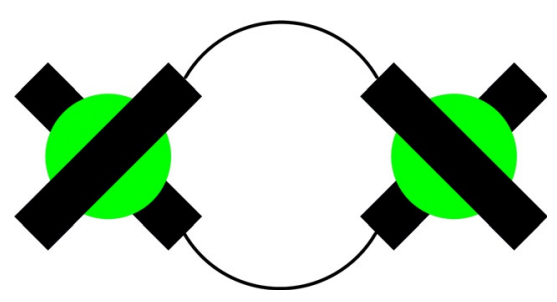

Figure 6. Schematic representation of the proposed structure for the 2:2 $\mathrm{Tb}^{\mathrm{II}}-1$ complex. Black: phenhomazine ligand, green: terbium(III) ion.

The preferred coordination of lanthanide ions by carboxylate groups is of a chelate nature, with each carboxylate group occupying two positions of the lanthanide's inner sphere (one with each oxygen atom). ${ }^{[52]}$ Therefore, four carboxylate groups would occupy the eight coordination positions of the lanthanide ion and leave no room for the binding of solvent molecules, as observed experimentally.

A spectrophotometric titration was also performed, as shown in Figure S27 (Supporting Information). The results confirm the presence of a main 1:1 complex, with a decrease in absorbance at $261 \mathrm{~nm}$ (and a slight bathochromic shift) up to the addition of one equivalent of $\mathrm{Tb}^{\text {III }}$ and the presence of two isosbestic points (at $243 \mathrm{~nm}$ and $268 \mathrm{~nm}$ ), which verify the nature of the equilibrium between the different species. An excess of $\mathrm{Tb}^{\mathrm{II}}$ in solution does not generate significant variations in the absorption spectra, showing that the geometry and proximities of the $p$-phenylenediamine moiety (main fluorophore) are similar in the 1:1 and 2:1 $\mathrm{Tb}^{\mathrm{III}}-1$ ratio complexes.

An NMR titration was performed by using diamagnetic La"I instead of paramagnetic Tb"II ions. Nevertheless, no substantial chemical shift variation was observed for any signal (Fig- 
ure S28, Supporting Information) showing that coordination would not provoke a significant conformational change. This result is more consistent with the 2:2 proposed structure, as the coordination of a single lanthanide(III) ion by the acetate arms of both aromatic rings would require their approximation in an almost parallel fashion and therefore a restraint on the diazocinic core.

\section{Study of terbium(III) luminescence quenching by copper(II) ions}

The addition of $\mathrm{Cu}^{\prime \prime}$ to a solution of a 1:1 $\mathrm{Tb}^{\mathrm{III}}-\mathbf{1}$ complex produces a steep decrease of the $\mathrm{Tb}^{\text {III }}$ luminescence, which becomes negligible after the incorporation of one equivalent of Cull (Figure 7).

The Stern-Volmer plot shows a non-linear response of $I_{0} / l$ as a function of $\mathrm{Cu}^{\text {II }}$ concentration, showing that a complex mechanism takes place, which cannot be described as purely static nor dynamic (Figure 8). ${ }^{[53]}$ Copper(II) addition also generates a shortening of the observed luminescence lifetimes, which indicates a dynamic component that affects the Tb"I excited states and favors its non-radiative deactivation. From a $\tau_{0} / \tau$ Stern-Volmer plot it is possible to obtain the second-order dynamic quenching constant, which results of $3.1 \times 10^{7} \mathrm{M}^{-1} \mathrm{~s}^{-1}$.

A similar study was finally performed by monitoring the absorbance of a 1:1 Tb"'II-1 complex upon incorporation of $\mathrm{Cu}^{\text {II }}$ (Figure 9). In this case, an increase in absorbance at $260 \mathrm{~nm}$, accompanied by a slight hypsochromic shift, is observed. The presence of an isosbestic point in $281 \mathrm{~nm}$ confirms the equilibrium of the ligand with the copper complex up to the addition of one equivalent. As was reported for the free ligand 1, in this
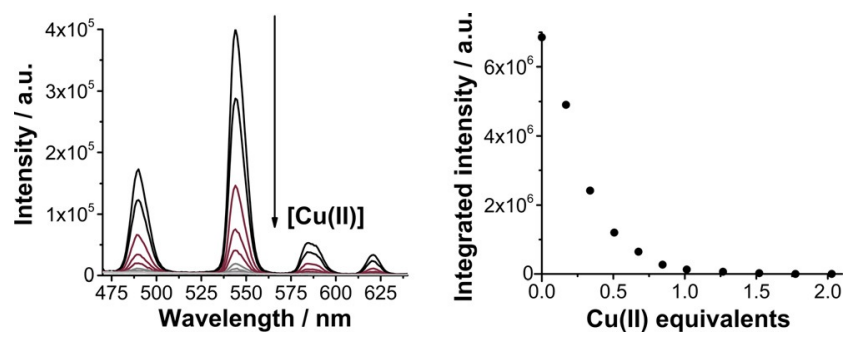

Figure 7. Spectrofluorimetric titration of a 1:1 $\mathrm{Tb}^{\mathrm{III}}-1$ mixture $\left(7.6 \times 10^{-6} \mathrm{M}\right)$ with $\mathrm{CuCl}_{2}$ in methanol. Left: $\mathrm{Tb}^{\mathrm{III}}$ emission spectra for $0-2.0$ equivalents of $C u^{\prime \prime}$ added; right: integrated emission intensity of the four ${ }^{5} D_{4} \rightarrow{ }^{7} F_{J}(J=6-3)$ bands $\left(\lambda_{\text {exc }}=312 \mathrm{~nm}\right)$.
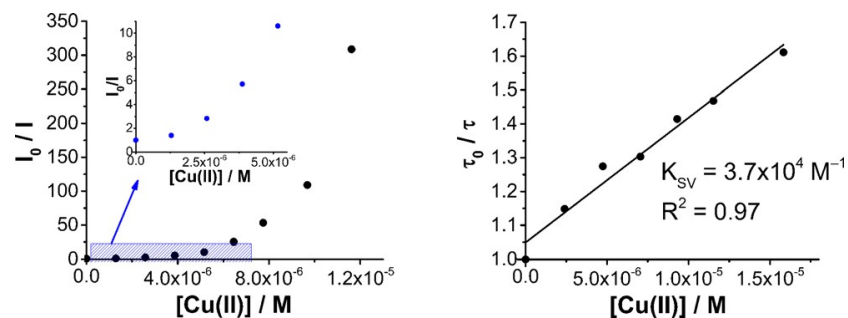

Figure 8. Stern-Volmer plots of $I_{0} / I$ (left, $7.6 \times 10^{-6} \mathrm{M}, \lambda_{\text {exc }}=312 \mathrm{~nm}$ ) and $\tau_{0} / \tau$ (right, $5.6 \times 10^{-5} \mathrm{M}, \lambda_{\text {exc }}=355 \mathrm{~nm}, \lambda_{\mathrm{em}}=545 \mathrm{~nm}$ ) of a 1:1 Tb'"I -1 mixture by addition of $\mathrm{CuCl}_{2}$, in methanol.

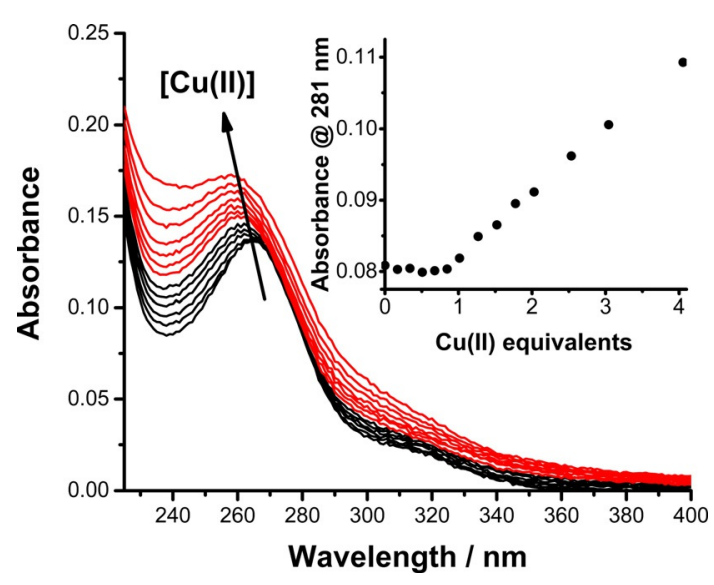

Figure 9. Spectrophotometric titration of a 1:1 $\mathrm{Tb}^{\mathrm{II}}-\mathbf{1}$ mixture $\left(7.6 \times 10^{-6} \mathrm{M}\right)$ with $\mathrm{CuCl}_{2}$ in methanol. Black: $0-1.0$ equivalents of $\mathrm{Cu}^{\prime \prime}$; red: $1.0-4.0$ equivalents of $\mathrm{Cu}^{\prime \prime}$

case further increase in $\mathrm{Cu}^{\text {Il }}$ concentration results in the loss of the isosbestic point, showing that the excess $\mathrm{Cu}^{\text {ll }}$ forms complexes with the solvent.

These results suggest that even in the presence of the 1:1 $\mathrm{Tb}^{\text {III }} \mathbf{1}$ complex, the Cul gets coordinated by the ligand 1, which in turn produces a decrease in the lanthanide luminescence. Nevertheless, it is not clear if Tb"l' coordination is preserved or modified by the incorporation of $\mathrm{Cu}^{\prime \prime}$, leading to a complex deactivation process. Even though a more thorough analysis of the quenching mechanism is out of the scope of the present work, it is interesting to point out that the SternVolmer constant obtained from lifetime measurements indicates that micromolar $\mathrm{Cu}$ "l concentrations could be detected for a $10 \%$ lifetime variation

\section{Conclusion}

In this work, we showed the preparation and characterization of the first phenhomazine-based potential "turn-off" sensor for copper(II) ions, based upon the coordination of lanthanides and transition metals. Even though the exact modes of coordination are not completely established, the experimental data strongly points toward the incorporation of the copper(II) ions in the diazocinic core of a boat-like structure by the synergistic action of the nitrogen atoms and the central acetate arms, whereas the terbium(III) ions are coordinated by the external acetate arms, forming possibly a self-assembled metallosupramolecular dinuclear structure.

The detection of copper(II) ions is based on their effects on the lanthanide luminescence. In particular, the synthesized sixarmed phenhomazine's terbium(III) complex shows a substantial decrease in luminescence intensity upon the addition of copper(II) ions, which could be used as a basis in the design of a "turn-off" sensor. In addition, the change in emission lifetimes could be used as well as a means of quantification of copper(II), taking advantage of the large values in the millisecond timescale and using time-resolved (gated) techniques, which 
can eliminate the interference of short-lived background fluorescence.

The ease and versatility of preparation of Tröger's bases with different aromatic scaffolds and the straightforward synthesis of phenhomazines from TBs demonstrate that the chosen pathway could be optimized to prepare different analogues. In addition, the design could also focus on the incorporation of the ligands in surfaces or three-dimensional matrices, to develop copper(II) sensors.

\section{Experimental Section}

\section{General remarks}

All reagents and solvents were purchased from commercial suppliers and used without further purification. All compounds were characterized by ${ }^{1} \mathrm{H}$ and ${ }^{13} \mathrm{C}$ nuclear magnetic resonance (NMR) spectroscopy by using a Bruker $600 \mathrm{MHz}$ spectrometer. ${ }^{1} \mathrm{H}$ NMR and ${ }^{13} \mathrm{C}$ NMR spectra were supplemented by $2 \mathrm{D}$ gradient selected correlation spectroscopy (COSY), multiplicity-edited heteronuclear single quantum coherence (HSQC), and heteronuclear multiple bond correlation (HMBC). Rotating frame Overhauser effect spectroscopy (ROESY) are denoted EXSY when the subject of interest is the chemical exchange. All NMR spectra were processed by using the MestReNova software. Chemical shifts $(\delta)$ are given in ppm downfield from TMS as the internal standard and coupling constant $(J)$ values are given in $\mathrm{Hz}$. Splitting patterns are abbreviated as follows: singlet $(\mathrm{s})$, doublet $(\mathrm{d})$, multiplet $(\mathrm{m})$, broad singlet (b.s.), and complex signal (c.s., mixture of different conformer's peaks that are not possible to integrate separately). ESI-Q-TOF-MS measurements were performed with a Bruker micrOTOF-Q II mass spectrometer running in the positive ion mode at $4.5 \mathrm{kV}$ at a desolvation temperature of $200^{\circ} \mathrm{C}$. High-resolution spectra were recorded with a $4 \mathrm{GHz}$ MaXis UHR QTOF mass spectrometer from Bruker Daltonics (Germany).

\section{General procedure and characterization of compounds}

4,10-Dimethyl-2,8-dinitro-6 $H, 12 H-5,11$-methanodibenzo[ $b, f][1,5]$ diazocine (4): 2-methyl-4-nitroaniline $(10.0 \mathrm{~g}, 0.066 \mathrm{~mol})$ was dissolved in trifluoroacetic acid (TFA, $80 \mathrm{~mL}$ ) previously cooled in an ice bath and paraformaldehyde $(4.77 \mathrm{~g}, 0.16 \mathrm{~mol})$ was added in portions. The reaction mixture was allowed to reach ambient temperature and was kept with stirring for $48 \mathrm{~h}$ and finally poured into water. The resulting suspension was basified to $\mathrm{pH} 9$ with $\mathrm{NaOH}$ $20 \%$ and the yellow solid was filtered and resuspended in hot acetone for $20 \mathrm{~min}$. After cooling, the mixture was kept at $-20^{\circ} \mathrm{C}$ for $16 \mathrm{~h}$ and afterwards the solid product was filtered and dried $(9.79 \mathrm{~g}, 0.029 \mathrm{~mol}, 87 \%)$. The crude product was pure according to NMR spectroscopic analysis.

${ }^{1} \mathrm{H}$ NMR (600 MHz, [D $\mathrm{D}_{6}$ DMSO): $\delta=7.97(\mathrm{~s}, 2 \mathrm{H}), 7.82(\mathrm{~s}, 2 \mathrm{H}), 4.68(\mathrm{~d}$, $J=17.3 \mathrm{~Hz}, 2 \mathrm{H}), 4.37(\mathrm{~s}, 2 \mathrm{H}), 4.32(\mathrm{~d}, J=17.3 \mathrm{~Hz}, 2 \mathrm{H}), 2.48 \mathrm{ppm}(\mathrm{s}$ $6 \mathrm{H}) ;{ }^{13} \mathrm{C}$ NMR $\left(150 \mathrm{MHz},\left[\mathrm{D}_{6}\right] \mathrm{DMSO}\right): \delta=152.5,143.2,135.0,129.8$, 123.9, 120.8, 66.6, 54.5, $17.3 \mathrm{ppm}$; HRMS (ESI): $\mathrm{m} / \mathrm{z}$ calcd for $\mathrm{C}_{17} \mathrm{H}_{17} \mathrm{~N}_{4} \mathrm{O}_{4}^{+}$: $341.1244[\mathrm{M}+\mathrm{H}]^{+}$; found: 341.1259.

4, 10-Dimethyl-6 $H, 12 H-5,11$-methanodibenzo[b,f][1,5]diazocine2,8-diamine (2): Dinitro-TB 4 (1.44 g, $4.2 \mathrm{mmol})$ and iron powder $(4.76 \mathrm{~g}, 85.3 \mathrm{mmol})$ were suspended in ethanol $(50 \mathrm{~mL})$ and acetic acid $(7.0 \mathrm{~mL}, 122.5 \mathrm{mmol})$ was added. The mixture was heated at reflux for $18 \mathrm{~h}$ under nitrogen atmosphere, then was poured into water and the excess iron powder was filtered. The aqueous solution was extracted with dichloromethane and the organic phase was washed with sat. aq. $\mathrm{NaHCO}_{3}$ and water, dried over $\mathrm{Na}_{2} \mathrm{SO}_{4}$ and evaporated to dryness. A white solid was obtained, which was pure according to NMR spectroscopic analysis $(1.18 \mathrm{~g}, 4.2 \mathrm{mmol}$, $99 \%)$.

'H NMR $\left(600 \mathrm{MHz}, \mathrm{CDCl}_{3}\right): \delta=6.41(\mathrm{~d}, J=2.0 \mathrm{~Hz}, 2 \mathrm{H}), 6.09(\mathrm{~d}, J=$ $2.0 \mathrm{~Hz}, 2 \mathrm{H}), 4.45(\mathrm{~d}, J=16.7 \mathrm{~Hz}, 2 \mathrm{H}), 4.27(\mathrm{~s}, 2 \mathrm{H}), 3.80(\mathrm{~d}, J=$ $16.7 \mathrm{~Hz}, 2 \mathrm{H}), 3.37$ (b.s., $4 \mathrm{H}), 2.31 \mathrm{ppm}(\mathrm{s}, 6 \mathrm{H}) ;{ }^{13} \mathrm{C} \mathrm{NMR}(150 \mathrm{MHz}$, $\left.\mathrm{CDCl}_{3}\right): \delta=142.3,137.7,133.8,129.0,116.3,110.4,68.1,55.4$, 17.0 ppm; HRMS (ESI): $\mathrm{m} / \mathrm{z}$ calcd for $\mathrm{C}_{17} \mathrm{H}_{21} \mathrm{~N}_{4}{ }^{+}: 281.1761[\mathrm{M+H}]^{+}$; found: 281.1759 .

Compound 3: To a solution of diamino-TB $2(0.60 \mathrm{~g}, 2.1 \mathrm{mmol})$ and diisopropylethylamine $(3.0 \mathrm{~mL}, 17 \mathrm{mmol})$ in acetonitrile $(25 \mathrm{~mL})$, sodium iodide $(0.41 \mathrm{~g}, 2.7 \mathrm{mmol})$ and tert-butyl bromoacetate $(3.0 \mathrm{~mL}, 20 \mathrm{mmol})$ were added under a nitrogen atmosphere, and the solution was heated at reflux for 4 days. The reaction mixture was then poured into water and extracted with dichloromethane, washed with water, dried over $\mathrm{Na}_{2} \mathrm{SO}_{4}$, and the solvent was evaporated under reduced pressure. The crude product was purified by column chromatography on silica gel (hexane/ethyl acetate), obtaining a light-yellow solid, which was pure according to NMR spectroscopic analysis (1.44 g, $1.5 \mathrm{mmol}, 70 \%)$.

Major conformer: ${ }^{1} \mathrm{H}$ NMR $\left(500 \mathrm{MHz}, \mathrm{CDCl}_{3}\right): \delta=6.28(\mathrm{~d}, J=2.1 \mathrm{~Hz}$, $2 \mathrm{H}), 6.18(\mathrm{~d}, J=2.1 \mathrm{~Hz}, 2 \mathrm{H}), 4.62(\mathrm{~d}, J=14.2 \mathrm{~Hz}, 2 \mathrm{H}), 4.14(\mathrm{~d}, J=$ $14.2 \mathrm{~Hz}, 2 \mathrm{H}), 4.04-3.87$ (c.s., $8 \mathrm{H}), 3.44(\mathrm{~d}, J=17.5 \mathrm{~Hz}, 2 \mathrm{H}), 3.34$ (d, $J=17.5 \mathrm{~Hz}, 2 \mathrm{H}), 2.18(\mathrm{~s}, 6 \mathrm{H}), 1.48(\mathrm{~s}, 18 \mathrm{H}), 1.45 \mathrm{ppm}(\mathrm{s}, 36 \mathrm{H})$; ${ }^{13} \mathrm{C}$ NMR $\left(125 \mathrm{MHz}, \mathrm{CDCl}_{3}\right): \delta=171.1,170.5,144.0,139.6,135.1$, 133.4, 115.0, 113.3, 81.4, 80.5, 55.7, 54.5-54.4, 28.2-28.0, 19.5 ppm. Minor conformer: ${ }^{1} \mathrm{H}$ NMR $\left(500 \mathrm{MHz}, \mathrm{CDCl}_{3}\right): \delta=6.32(\mathrm{~d}, J=2.4 \mathrm{~Hz}$, $2 \mathrm{H}), 6.23(\mathrm{~d}, J=2.4 \mathrm{~Hz}, 2 \mathrm{H}), 4.19(\mathrm{~d}, J=14.4 \mathrm{~Hz}, 2 \mathrm{H}), 4.04-3.87$ (c.s., $8 \mathrm{H}), 4.05(\mathrm{~d}, J=14.4 \mathrm{~Hz}, 2 \mathrm{H}), 3.64(\mathrm{~d}, J=16.9 \mathrm{~Hz}, 2 \mathrm{H}), 3.27(\mathrm{~d}, J=$ $17.0 \mathrm{~Hz}, 2 \mathrm{H}), 2.31(\mathrm{~s}, 6 \mathrm{H}), 1.48(\mathrm{~s}, 36 \mathrm{H}), 1.34 \mathrm{ppm}(\mathrm{s}, 18 \mathrm{H}) ;{ }^{13} \mathrm{C} \mathrm{NMR}$ $\left(125 \mathrm{MHz}, \mathrm{CDCl}_{3}\right): \delta=171.7,170.4,145.4,143.3,140.6,138.5,113.3$, $112.7,81.5,80.2,58.5,54.5-54.4,28.2-28.0,19.4$ ppm. Ratio major/ minor: 58:42. HRMS (ESI) $\mathrm{m} / z$ calcd for $\mathrm{C}_{53} \mathrm{H}_{81} \mathrm{~N}_{4} \mathrm{O}_{12}{ }^{+}$: 953.5846 $[\mathrm{M}+\mathrm{H}]^{+}$; found: 953.5854 .

Compound 1: To a solution of hexa-tert-butyl ester $3(0.42 \mathrm{~g}$, $0.44 \mathrm{mmol})$ in dichloromethane $(40 \mathrm{~mL})$, trifluoroacetic acid $(4.0 \mathrm{~mL}, 0.05 \mathrm{~mol})$ was added in an ice bath. The resulting solution was allowed to reach room temperature and stirred for 4 days. The evaporation of the solvent under reduced pressure and dropwise addition of diethyl ether gave the title compound, which was filtered. The product was obtained in a quantitative yield and was pure according to NMR analysis $(0.27 \mathrm{~g}, 0.44 \mathrm{mmol}, 100 \%)$.

${ }^{1} \mathrm{H}$ NMR $\left(600 \mathrm{MHz}, \mathrm{CD}_{3} \mathrm{OD}\right): \delta=6.34(\mathrm{~s}, 2 \mathrm{H}), 6.16(\mathrm{~s}, 2 \mathrm{H}), 4.92(\mathrm{~d}, J=$ $14.4 \mathrm{~Hz}, 2 \mathrm{H}), 4.61(\mathrm{~d}, J=14.4 \mathrm{~Hz}, 2 \mathrm{H}), 4.46-4.34(\mathrm{~m}, 4 \mathrm{H}), 4.14-4.04$ $(\mathrm{m}, 8 \mathrm{H}), 2.41 \mathrm{ppm}(\mathrm{s}, 6 \mathrm{H}) ;{ }^{13} \mathrm{C}$ NMR $\left(150 \mathrm{MHz}, \mathrm{CD}_{3} \mathrm{OD}\right): \delta=174.6$, $172.5,149.2,136.9,134.1,130.4,116.5,110.8,61.5,56.7,53.8$, $19.4 \mathrm{ppm}$; HRMS (ESI) $\mathrm{m} / \mathrm{z}$ calcd for $\mathrm{C}_{28} \mathrm{H}_{30} \mathrm{~N}_{4} \mathrm{O}_{12}{ }^{2-}$ : 307.0936 $[\mathrm{M}-2 \mathrm{H}]^{2-}$; found: 307.0933 .

Compound 5: To a solution of diamino-TB $2(1.53 \mathrm{~g}, 5.5 \mathrm{mmol})$ and diisopropylethylamine $(4.8 \mathrm{~mL}, 28 \mathrm{mmol})$ in acetonitrile $(65 \mathrm{~mL})$, tert-butyl bromoacetate $(4.9 \mathrm{~mL}, 33 \mathrm{mmol})$ was added under a nitrogen atmosphere, and the solution was heated at reflux for 4 days. The reaction mixture was then poured into water and extracted with dichloromethane, washed with water, dried over $\mathrm{Na}_{2} \mathrm{SO}_{4}$, and the solvent was evaporated under reduced pressure. The crude product was purified by column chromatography on silica gel (hexane/ethyl acetate), obtaining a light-yellow solid, which was pure according to NMR spectroscopic analysis $(1.80 \mathrm{~g}$, $2.5 \mathrm{mmol}, 45 \%)$.

${ }^{1} \mathrm{H}$ NMR $\left(600 \mathrm{MHz}, \mathrm{CDCl}_{3}\right): \delta=6.30(\mathrm{~d}, J=2.9 \mathrm{~Hz}, 2 \mathrm{H}), 5.95(\mathrm{~d}, J=$ $2.9 \mathrm{~Hz}, 2 \mathrm{H}), 4.45(\mathrm{~d}, J=16.7 \mathrm{~Hz}, 2 \mathrm{H}), 4.25(\mathrm{~s}, 2 \mathrm{H}), 3.94-3.87(\mathrm{~m}, 8 \mathrm{H})$, 
$3.81(\mathrm{~d}, J=16.7 \mathrm{~Hz}, 2 \mathrm{H}), 2.32(\mathrm{~s}, 6 \mathrm{H}), 1.43 \mathrm{ppm}(\mathrm{s}, 18 \mathrm{H}) ;{ }^{13} \mathrm{C} \mathrm{NMR}$ $\left(150 \mathrm{MHz}, \mathrm{CDCl}_{3}\right): \delta=170.5,144.4,137.3,133.4,128.8,113.7,107.9$, 81.5, 68.0, 55.6, 54.6, 28.1, 17.5 ppm; HRMS (ESI): $\mathrm{m} / \mathrm{z}$ calcd for $\mathrm{C}_{41} \mathrm{H}_{61} \mathrm{~N}_{4} \mathrm{O}_{8}{ }^{+}$: $737.4484[\mathrm{M}+\mathrm{H}]^{+}$; found: 737.4488.

Compound 6: To a solution of tetra-tert-butyl ester $5(0.59 \mathrm{~g}$, $0.80 \mathrm{mmol})$ in dichloromethane $(50 \mathrm{~mL})$, trifluoroacetic acid $(6.0 \mathrm{~mL}, 0.08 \mathrm{~mol})$ was added in an ice bath. The resulting solution was allowed to reach room temperature and stirred for 4 days. The evaporation of the solvent under reduced pressure and dropwise addition of diethyl ether gave the title compound, which was filtered. The product was obtained in a quantitative yield and was pure according to NMR analysis $(0.41 \mathrm{~g}, 0.80 \mathrm{mmol}, 100 \%)$.

${ }^{1} \mathrm{H}$ NMR $\left(600 \mathrm{MHz}, \mathrm{D}_{2} \mathrm{O}+\mathrm{NaOD}\right): \delta=6.23(\mathrm{~s}, 2 \mathrm{H}), 5.89(\mathrm{~s}, 2 \mathrm{H}), 4.37$ $(\mathrm{d}, J=17.0 \mathrm{~Hz}, 2 \mathrm{H}), 4.12(\mathrm{~s}, 2 \mathrm{H}), 3.89(\mathrm{~d}, J=17.0 \mathrm{~Hz}, 2 \mathrm{H}), 3.71(\mathrm{~s}$, $8 \mathrm{H}), 2.22 \mathrm{ppm}(\mathrm{s}, 6 \mathrm{H}) ;{ }^{13} \mathrm{C}$ NMR $\left(150 \mathrm{MHz}, \mathrm{D}_{2} \mathrm{O}+\mathrm{NaOD}\right): \delta=179.7$, 145.8, 133.4, 132.8, 128.0, 113.1, 106.8, 67.1, 55.6, 54.8, 16.7 ppm; HRMS (ESI) $\mathrm{m} / \mathrm{z}$ calcd for $\mathrm{C}_{25} \mathrm{H}_{26} \mathrm{~N}_{4} \mathrm{O}_{8}{ }^{2-}: 255.0881[\mathrm{M}-2 \mathrm{H}]^{2-}$; found: 255.0881.

\section{Photophysical measurements}

UV/Vis absorption spectra were measured by using a Shimadzu UV-3600 spectrophotometer with $1.00 \mathrm{~cm}$ optical pass quartz cuvettes with Teflon caps. Baselines were obtained with pure solvents, slow spectral acquisition speed, and $1 \mathrm{~nm}$ of spectral width. Emission and excitation spectra were obtained by using a PTI QuantaMaster QM4 spectrofluorometer in $1.00 \mathrm{~cm}$ optical pass fluorescence quartz cuvettes with Teflon caps in right angle geometry. Appropriate excitation and emission wavelengths were chosen for each case, and emission filters were used when necessary. Spectra were acquired with $0.2 \mathrm{~s}$ integration time and $1 \mathrm{~nm}$ steps. Slits were adjusted between 0.25 and $1.00 \mathrm{~mm}$ to obtain adequate signal/noise ratios but avoiding saturation of detection. Emission spectra were corrected by using the mathematical function provided by the instrumental software.

Fluorescence quantum yield determination was performed by using the relative method according to the guidelines suggested by the International Union of Pure and Applied Chemistry (IUPAC) and by Rurak. ${ }^{[54,55]}$ Low absorbance $(A<0.1)$ solutions were used to avoid inner filter effects and errors produced by an uneven distribution of excited species in the detection volume. In every case, the same cuvette was used for the sample and reference and the excitation was performed at a wavelength where both compounds presented significant absorption and that allowed full registration of their emission spectra. If possible, an absorption maximum (or minimum) was chosen. Quinine sulfate in $0.5 \mathrm{M}$ sulfuric acid was chosen as the reference. ${ }^{[56]}$ Quantum yields were obtained from the slope of the linear regression of the graph of the integrated emission intensity $v 1-10^{-A(\lambda)}$, where $A(\lambda)$ is the absorbance at the excitation wavelength. At least four spectra for different absorbances in the 0-0.1 range were obtained, to remove spurious light influence and to guarantee emission linearity with respect to absorption. A $10 \%$ error is estimated for quantum yield measurements.

Fluorescence lifetimes were performed using $355 \mathrm{~nm}$ excitation with a Nd:YAG Spectron Laser Systems tripled frequency laser, with exit pulse width of $8 \mathrm{~ns}$ and repetition frequency of $1 \mathrm{MHz}$. Excitation pulses were adequately attenuated for irradiation of the samples, which were set in $0.20-1.00 \mathrm{~cm}$ optical pass fluorescence quartz cuvettes with Teflon caps in right angle geometry. A UG-11 filter was employed to remove green light of doubled frequency from the laser $(532 \mathrm{~nm})$ and detection was done at $545 \mathrm{~nm}$, with a WG-400 filter set to eliminate incident light. Light was measured with a Hamamatsu R928 photomultiplier tube and the acquisition was realized with a HP54504A digital oscilloscope. A total of 256 pulses were averaged and the decays were adjusted to a mono-exponential fit. A $10 \%$ error is estimated for luminescence lifetime measurements.

\section{Acknowledgments}

This work was supported by Agencia Nacional de Promoción Científica y Tecnológica (PICT 2013-2331 to J.A.R.) and Universidad de Buenos Aires (UBACyT 20020130100826BA to J.A.R.). L.T. thanks the Bec.ar program for a scholarship to conduct an 8 month stay at the Centre de Biophysique Moléculaire (CNRS UPR4301, France). The work in France was supported by La Ligue Contre le Cancer, la Région Centre and I'Agence Nationale de la Recherche (NIRA-ANR-13-BS08-0011). S.P. acknowledges support from the Institut National de la Santé et de la Recherche Médicale (INSERM).

\section{Conflict of interest}

The authors declare no conflict of interest.

Keywords: copper • lanthanides • luminescence
phenhomazines $\cdot$ sensors

[1] M. Rehman, L. Liu, Q. Wang, M. H. Saleem, S. Bashir, S. Ullah, D. Peng, Environ. Sci. Pollut. Res. 2019, 26, 18003-18016.

[2] J. R. Lamichhane, E. Osdaghi, F. Behlau, J. Köhl, J. B. Jones, J. N. Aubertot, Agron. Sustainable Dev. 2018, 38, 28.

[3] D. J. Waggoner, T. B. Bartnikas, J. D. Gitlin, Neurobiol. Dis. 1999, 6, 221 230.

[4] F. Tisato, C. Marzano, M. Porchia, M. Pellei, C. Santini, Med. Res. Rev. 2009, 30, 708-749.

[5] S. Lutsenko, C. Washington-Hughes, M. Ralle, K. Schmidt, J. Biol. Inorg. Chem. 2019, 24, 1179-1188.

[6] S. V. Eliseeva, I. P. Golovach, V. S. Liasotskyi, V. P. Antonovich, S. Petoud, S. B. Meshkova, J. Lumin. 2016, 171, 191-197.

[7] L. Fabbrizzi, M. Licchelli, P. Pallavicini, D. Sacchi, A. Taglietti, Analyst 1996, 121, 1763-1768.

[8] L. Fabbrizzi, M. Licchelli, P. Pallavicini, A. Perotti, A. Taglietti, D. Sacchi, Chem. Eur. J. 1996, 2, 75-82.

[9] M. Clerc, F. Heinemann, B. Spingler, G. Gasser, Inorg. Chem. 2020, 59, $669-677$.

[10] M. Turel, A. Duerkop, A. Yegorova, Y. Scripinets, A. Lobnik, N. Samec, Anal. Chim. Acta 2009, 644, 53-60.

[11] B. K. McMahon, T. Gunnlaugsson, Tetrahedron Lett. 2010, 51, 5406-5410.

[12] Y. Zheng, W. Zhang, C. Tan, S. Zheng, Q. Wang, S. Cai, J. Fluoresc. 2010, 21, 1117-1122.

[13] L. Chen, H. Tan, F. Xu, L. Wang, Luminescence 2018, 33, 161-167.

[14] R. R. Zairov, R. N. Nagimov, S. N. Sudakova, D. V. Lapaev, V. V. Syakaev, G. S. Gimazetdinova, A. D. Voloshina, M. Shykula, I. R. Nizameev, A. I. Samigullina, A. T. Gubaidullin, S. N. Podyachev, A. R. Mustafina, Microchim. Acta 2018, 185, 386.

[15] J.-C. G. Bünzli, C. Piguet, Chem. Soc. Rev. 2005, 34, 1048-1077.

[16] S. V. Eliseeva, J.-C. G. Bünzli, Chem. Soc. Rev. 2010, 39, 189-227.

[17] J.-C. G. Bünzli, Acc. Chem. Res. 2006, 39, 53-61.

[18] L. Armelao, S. Quici, F. Barigelletti, G. Accorsi, G. Bottaro, M. Cavazzini, E. Tondello, Coord. Chem. Rev. 2010, 254, 487-505.

[19] J.-C. G. Bünzli, Coord. Chem. Rev. 2015, 293-294, $19-47$.

[20] C. S. Hampton, M. Harmata, Tetrahedron 2016, 72, 6064-6077.

[21] M. S. Hussain, Saeed-ur-Rehman, Z. Naturforsch. 1978, 33, 67-74.

[22] M. S. Hussain, Saeed-ur-Rehman, Inorg. Chim. Acta 1982, 60, 231-238. 
[23] M. S. Hussain, J. Chem. Soc. Dalton Trans. 1982, 2545-2547.

[24] M. L. Cable, D. J. Levine, J. P. Kirby, H. B. Gray, A. Ponce, Luminescent Lanthanide Sensors, in Advances in Inorganic Chemistry, 63, 2011, pp. 1-45.

[25] M. Du, X. H. Bu, J. Mol. Struct. 2004, 692, 195-199.

[26] M. Yu, X. Wang, M. Hu, J. Coord. Chem. 2015, 68, 520-528.

[27] Y. Hamada, S. Mukai, Tetrahedron: Asymmetry 1996, 7, 2671 - 2674.

[28] Y. Miyahara, K. Izumi, A. A. Ibrahim, T. Inazu, Tetrahedron Lett. 1999, 40, $1705-1708$.

[29] M. Kazem-Rostami, Synthesis 2016, 48, 1214-1222.

[30] U. Kiehne, T. Weilandt, A. Lutzen, Org. Lett. 2007, 9, 1283-1286.

[31] Y. Liu, X. Dong, J. Sun, C. Zhong, B. Li, X. You, Analyst 2012, 137, 1837 1845.

[32] D. R. Bond, J. L. Scott, J. Chem. Soc. Perkin Trans. 2 1991, 47-51.

[33] D. A. Lenev, D. G. Golovanov, K. A. Lyssenko, R. G. Kostyanovsky, Tetrahedron: Asymmetry 2006, 17, $2191-2194$.

[34] O. Trapp, G. Trapp, J. Kong, U. Hahn, F. Vögtle, V. Schurig, Chem. Eur. J. 2002, 8, 3629-3634.

[35] F. Ishiwari, N. Takeuchi, T. Sato, H. Yamazaki, R. Osuga, J. N. Kondo, T. Fukushima, ACS Macro Lett. 2017, 6, 775-780.

[36] M. Tafazzoli, A. Ziyaei-Halimjani, M. Ghiasi, M. Fattahi, M. R. Saidi, J. Mol. Struct. 2008, 886, 24-31.

[37] A. S. Mereshchenko, S. K. Pal, K. E. Karabaeva, P. Z. El-Khoury, A. N. Tarnovsky, J. Phys. Chem. A 2012, 116, 2791-2799.

[38] A. Guillou, L. M. P. Lima, D. Esteban-Gómez, R. Delgado, C. Platas-Iglesias, V. Patinec, R. Tripier, Dalton Trans. 2019, 48, 8740-8755.

[39] J. Devi, M. Yadav, D. K. Jindal, D. Kumar, Y. Poornachandra, Appl. Organomet. Chem. 2019, 33, e5154.

[40] L. Jimeno, I. Alkorta, J. E. Anderson, R. M. Claramunt, J. L. Lavandera, New J. Chem. 1998, 22, 1079-1083.

[41] M. Latva, H. Takalo, V.-M. Mukkala, C. Matachescu, J. C. Rodriguez-Ubis, J. Kankare, J. Lumin. 1997, 75, 149-169.
[42] G. Hou, H. Li, W.-Z. Li, P. Yan, X. Su, G. Li, Cryst. Growth Des. 2013, 13, $3374-3380$.

[43] R. C. Holz, W. W. De Horrocks, C. A. Chang, W. D. J. Horrocks, C. A. Chang, Inorg. Chem. 1991, 30, 3270-3275.

[44] A. Jarzebski, C. Tenten, C. Bannwarth, G. Schnakenburg, S. Grimme, A. Lützen, Chem. Eur. J. 2017, 23, 12380-12386.

[45] T. Weilandt, U. Kiehne, J. Bunzen, G. Schnakenburg, A. Lützen, Chem. Eur. J. 2010, 16, 2418-2426.

[46] T. Weilandt, U. Kiehne, G. Schnakenburg, A. Lützen, Chem. Commun. 2009, 2320-2322.

[47] C. Benkhäuser, A. Lützen, Beilstein J. Org. Chem. 2015, 11, 693-700.

[48] M. Elhabiri, J. Hamacek, J.-C. G. Bünzli, A. M. Albrecht-Gary, Eur. J. Inorg. Chem. 2004, 51-62.

[49] N. Martin, J.-C. G. Bünzli, V. McKee, C. Piguet, G. Hopfgartner, Inorg. Chem. 1998, 37, 577-589.

[50] C. Butler, S. Goetz, C. M. Fitchett, P. E. Kruger, T. Gunnlaugsson, Inorg. Chem. 2011, 50, 2723-2725.

[51] Q. Cheng, W. Y. Huang, Q. H. Huang, Y. J. Xiong, J. F. Fang, Y. Li, F. F. Zhu, S. T. Yue, J. Coord. Chem. 2015, 68, 1980-1996.

[52] R. Janicki, A. Mondry, P. Starynowicz, Coord. Chem. Rev. 2017, 340, 98 133.

[53] J. R. Lakowicz, Principles of Fluorescence Spectroscopy, Springer International, New York, 2006.

[54] A. M. Brouwer, Pure Appl. Chem. 2011, 83, 2213-2228.

[55] Standardization and Quality Assurance in Fluorescence Measurements I (Ed.: U. Resch-Genger), Springer International, New York, 2008.

[56] S. R. Meech, D. Phillips, J. Photochem. 1983, 23, 193-217.

Manuscript received: May 7, 2020

Accepted manuscript online: June 5, 2020

Version of record online: September 11, 2020 